\title{
In Memory of Viktor Ivanovich Mitashov (June 3, 1937-April 24, 2007)
}

\section{DOI: $10.1134 / \mathrm{S} 1062359008020015$}

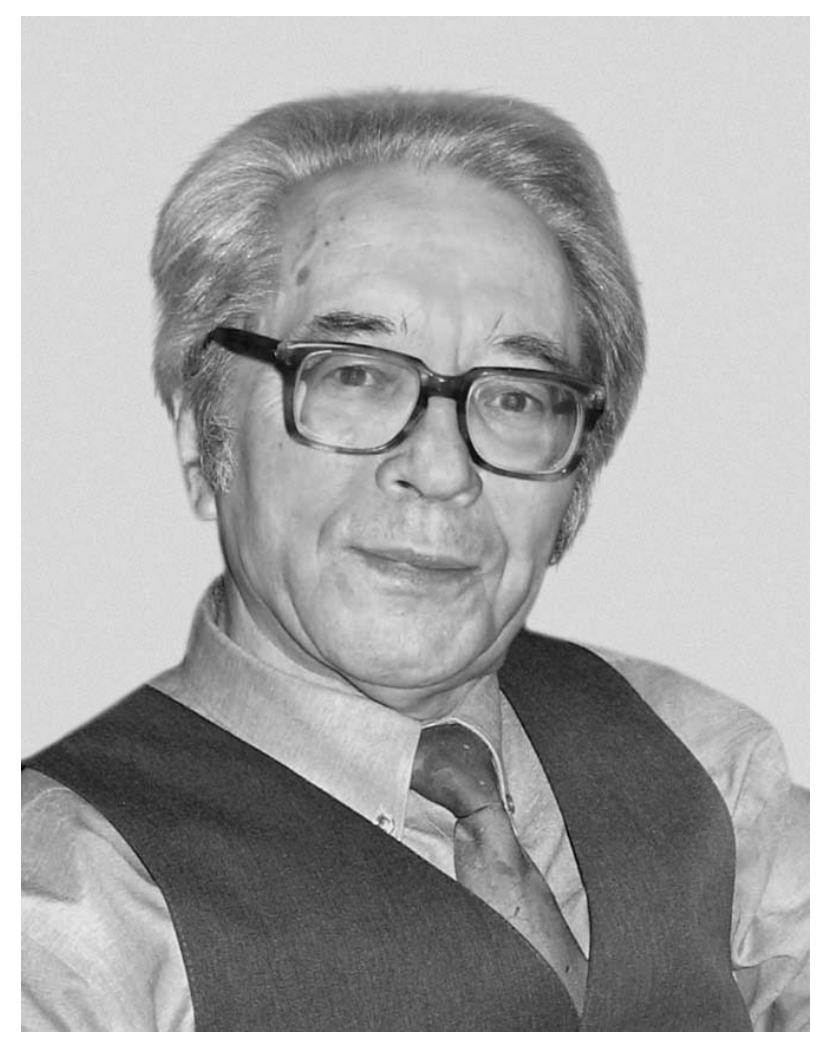

The scientific community has lost an outstanding scientist, and the Kol'tsov Institute of Developmental Biology of the Russian Academy of Sciences has lost an indispensable researcher. Professor Viktor Ivanovich Mitashov, Doctor of Biology, deputy director of the institute, head of the Laboratory of Regeneration, a person of admirable qualities has passed away.
Mitashov was a widely recognized specialist in regeneration mechanisms and transdifferentiation at the cellular, tissue, and molecular genetic levels. He was the first to obtain invaluable data on the time of genome reprogramming in pigment epithelial cells transdifferentiating into retinal cells in adult newts. The results of these studies allow us to consider Mitashov the leading researcher in regeneration, which is one of the crucial problems in developmental biology.

Mitashov recently initiated comparative studies on the molecular genetic mechanisms of eye tissue regeneration and development in vertebrates, including humans. The research program developed by Mitashov is intended for identifying the regulatory genes and signal pathways that control the development and regeneration of eye tissues and analyzing their structures and functions. It has been demonstrated that the expression of genes belonging to the basic regulatory cascade controlling development is activated in neuroblasts of the regenerating retina. These studies are especially important for determining the functional role of stem cells found in adult mammalian and human eyes; they are aimed at the search for the cellular sources of repair of the adult human retina. Mitashov has made a considerable contribution to the development of current concepts on the general patterns of cell differentiation.

Mitashov was the executive editor of the Izvestiya RAN. Seriya Biologicheskaya (Biology Bulletin) and always took active part in the publication of this journal. Studies performed at the Kol'tsov Institute of Developmental Biology of the Russian Academy of Sciences in the framework of Mitashov's program are published in the section "Cell Biology" of this issue; Mitashov supervised three of these studies. The authors dedicate their articles to the memory of Viktor Ivanovich Mitashov. 